\title{
Antifungal activity from 0 cimum gratissimum L. towards Cryptococcus neoformans
}

\section{Janine de Aquino Lemos, Xisto Sena Passos, O rionalda de Fátima Lisboa Fernandes, José Realino de Paula**, Pedro Henrique Ferri* , Lúcia Kioko Hasimoto e Souza, Aline de Aquino Lemos, Maria do Rosário Rodrigues Silva/ ${ }^{+}$}

\author{
Laboratório de Micologia, Instituto de Patologia Tropical e Saúde Pública *Laboratório de Produtos Naturais, Instituto de \\ Química **Laboratório de Farmacognosia, Faculdade de Farmácia, Universidade Federal de Goiás, Caixa Postal 131, \\ 74605-050 Goiânia, GO, Brasil
}

\begin{abstract}
Cryptococcal infection had an increased incidence in last years due to the explosion of acquired immune deficiency syndrome epidemic and by using new and effective immunosuppressive agents. The currently antifungal therapies used such as amphotericin B, fluconazole, and itraconazole have certain limitations due to side effects and emergence of resistant strains. So, a permanent search to find new drugs for cryptococcosis treatment is essential. Ocimum gratissimum, plant known as alfavaca (Labiatae family), has been reported earlier with in vitro activity against some bacteria and dermatophytes. In our work, we study the in vitro activity of the ethanolic crude extract, ethyl acetate, hexane, and chloroformic fractions, essential oil, and eugenol of $\mathrm{O}$. gratissimum using an agar dilution susceptibility method towards 25 isolates of Cryptococcus neoformans. All the extracts of $\mathrm{O}$. gratissimum studied showed activity in vitro towards $\mathrm{C}$. neoformans. Based on the minimal inhibitory concentration values the most significant results were obtained with chloroformic fraction and eugenol. It was observed that chloroformic fraction inhibited 23 isolates (92\%) of C. neoformans at a concentration of $62.5 \mu \mathrm{g} / \mathrm{ml}$ and eugenol inhibited 4 isolates (16\%) at a concentration of $0.9 \mu \mathrm{g} / \mathrm{ml}$. This screening may be the basis for the study of $\mathrm{O}$. gratissimum as a possible antifungal agent.
\end{abstract}

Key words: Ocimum gratissimum - essential oil - eugenol - Cryptococcus neoformans

Cryptococcal infections have increased dramatically over the last years. This high incidence can be due in large part to the explosion of acquired immune deficiency syndrome (AIDS) epidemic around the world and the use of more potent immunosuppressive agents by increasing numbers of solid organ transplant recipients (Mitchell \& Perfect 1995, Dromer et al. 1996).

Cryptococcal meningitis, the most common infection of cryptococcosis is usually chronic and uniformly fatal if untreated (Collazos 2003). Some antifungal drugs, such as polyene macrolides (amphotericin B) and azoles (itraconazole and fluconazole) are currently used in antifungal therapies with certain limitations due to side effects as toxicity and emergence of resistant strains (Terrel 1999, Saag et al. 2000). The lack of response to treatment and resistance in vitro to fluconazole, the drug that now commands maintenance treatment protocols for AIDS patients has began to emerge with Cryptococcus neoformans var. neoformans in immunocompromissed patients undergoing prolonged azole treatment (Alves et al. 1997, Momoff \& Parrish 2003). Besides, the development of amphotericin B resistant of isolates $C$. neoformans var. neoformans has been related by De Bedout et al. (1999), indicating the need for a permanent search and development of new drugs.

${ }^{+}$Corresponding author. E-mail: rosario@iptsp.ufg.br Received 19 March 2004

Accepted 20 December 2004
The medicinal plants have been used for several purposes including antimicrobial effects and have showed inhibition of growth to fungi. Caryocar brasiliensis, plant widely distributed in Brazil, has in vitro activity against Paracoccidioides brasiliensis and $C$. neoformans (Passos et al. 2003) while Hyptis ovalifolia, plant native from Brazilian cerrado, has inhibitory effect on dermatophytes (Souza et al. 2002). We are interested on antifungal activity of Ocimum gratissimum, plant known as alfavaca cravo, which has presented in vitro inhibitory effect against bacteria as Staphylococcus aureus, Escherichia coli, and some fungi as dermatophytes (Lima et al. 1993, Nakamura et al. 1999).

The occurrence of cryptococcosis in Goiânia (Fernandes et al. 2003) and its importance in immunocom-promised patients justify in studying Cryptococcus species in this city localized in the Brazilian midwest region. In this paper the antifungal activity of ethanolic crude extract, ethyl acetate, hexane and chloroformic fractions, essential oils and eugenol from $O$. gratissimum leaves towards 25 isolates of $C$. neoformans, important pathogen commonly found in our geographic area (Fernandes et al. 2003), was investigated.

\section{MATERIALS AND METHODS}

Plant material - O. gratisimum was collected in Goiânia city, state of Goiás, Brazil (768 m, 33.3"'S/ 1640'39.5'W $49^{\circ} 14^{\prime}$ ) in June 2001, at 11:00 am. Voucher specimens (number 27157) were deposited at the herbarium of the Universidade Federal de Goiás (UFG).

Powdered air-dried leaves of $O$. gratissimum were successively extracted in cold with $96 \%$ ethanol as solvent at 
room temperature. Ethanolic extract was concentrated and dried under reduced pressure at $40^{\circ} \mathrm{C}$ in a vapor motor and dispersed in methanol/water 7:3 mixture. The resultant dispersion was filtered in Celite, to remove chlorophyll (Fernandes et al. 1997) and lately extracted with hexane, chloroform, and ethyl acetate to obtain the hexane, chloroformic, and ethyl acetate fractions free of chlorophylls and all solvents. The essential oil of $O$. gratissimum leaves was isolated by hydrodistillation in a Clevenger type apparatus for $4 / 5 \mathrm{~h}$, yield the pure oil which was dried by treating with anhydrous $\mathrm{Na}_{2} \mathrm{SO}_{4}$.

Eugenol (Sigma), main constituent of the essential oil of $O$. gratissimum was commercially obtained.

Chemical analysis of essential oil - Oil sample analysis was performed on a Shimadzu QP5050A gas chromatograph interfaced to a mass spectrometer (GC/MS) instrument employing the following conditions: fused silica capillary column (CBP-5; $30 \mathrm{~m} \times 0.25 \mu \mathrm{m} \times 0.25 \mu \mathrm{m}$ ) which was programmed as follows: $60^{\circ} \mathrm{C}$ for $2 \mathrm{~min}$ and then up to $240^{\circ} \mathrm{C}$ at $3^{\circ} \mathrm{C} / \mathrm{min}$, then to $270^{\circ} \mathrm{C}$ at $10^{\circ} \mathrm{C} /$ min ending with a $10 \mathrm{~min}$ at $270^{\circ} \mathrm{C}$. The carrier gas was $\mathrm{He}$ at a flow rate of 1 $\mathrm{ml} / \mathrm{min}$, split mode, with ratio of $1: 5$, and injection volume of $1 \mu \mathrm{l}$ in $\mathrm{CH}_{2} \mathrm{Cl}_{2}$ and the ionization voltage, $70 \mathrm{EV}$. The calculation of the retention indexes was made through co-injection with $\mathrm{C}_{8}-\mathrm{C}_{32} \mathrm{n}$ alkanes series (Van Den Doll \& Kratz 1963). Identification of the oil constituents was made based on the retentions indexes (Adams 1995) and by comparison of mass spectra with the computer search using NIST libraries of mass spectral data. Percentage composition of the oil sample was calculated from GC peak areas.

Microorganisms - All the 25 strains of C. neoformans used in this study were clinical isolates from human immunodeficiency virus-infected patients with cryptococcal meningitis, obtained at Laboratório Central de Saúde Pública Dr Giovanni Cysneiros, Goiânia, GO, Brazil. Candida albicans ATCC 10231, was used as reference strains for susceptibility tests and was included whenever a test was run. The stock cultures were maintained on Sabouraud dextrose agar medium (SDA, Difco) at $25^{\circ} \mathrm{C}$. Each isolate was subcultured at least twice on Sabouraud dextrose agar to ensure purity and optimal growth before testing.

Antifungal assay - The dilution in agar technique was used to test the plant extracts against $C$. neoformans (Alves \& Cury 1992, Passos et al. 2003). Plant extracts, essential oil, and eugenol (dry and solvent free) were solubilized in $1 \mathrm{ml}$ of dimethyl sulfoxide (DMSO) and serially two-fold diluted in RPMI-1640 broth with L-glutamine and without sodium bicarbonate (Sigma), buffered to $\mathrm{pH} 7.0$ with $0.165 \mathrm{M}$ MOPS (morpholinepropanesulfonic acid) to obtain a concentration range of $10-10,000 \mu \mathrm{g} / \mathrm{ml}$. Of this solution, $2 \mathrm{ml}$ were transferred into sterile Petri dishes and $18 \mathrm{ml}$ of liquefied RPMI agar at $45^{\circ} \mathrm{C}$ were added and immediately mixed, obtaining a concentration range of 1.0$1000 \mu \mathrm{g} / \mathrm{ml}$.

Cell suspensions were prepared in $0.85 \%$ saline and adjusted to an OD $(530 \mathrm{~nm})$ equivalent to $1 \times 10^{6} \mathrm{UFC} / \mathrm{ml}$. These suspensions $(3 \mu \mathrm{l})$ were inoculated on agar plates incubated at $37^{\circ} \mathrm{C}$ for $48-72 \mathrm{~h}$. Cultures containing only RPMI 1640 medium diluted in the same conditions, were used as controls. The minimum inhibitory concentration (MIC) was defined as the lowest concentration able to inhibit any visible fungal growth compared with that of plant free growth control. Cultures containing only DMSO diluted in the same conditions, which did not influence fungal growth, were used as controls. The sensitivity of all $C$. neoformans strains to itraconazole was performed using the same technique. Itraconazole (Janssen) was diluted in polyethylene glycol (PEG-Fisher Scientific). The MIC for itraconazole was defined as the lowest concentration of drug that produced an $80 \%$ reduction in fungal growth compared with that of drug-free growth control. All antifungal assays were tested in duplicated.

\section{RESULTS}

Sample hydrodistillation of $O$. gratissimum leaves produced a clear, colorless to pale yellow oil, with a yield of $0.69 \%$. The essential oil was a mixture with 21 compounds. The main compounds of the $O$. gratissimum leaves oil were eugenol (57.82\%), followed by $\alpha$-bisabolene (17.19\%), and thymol (9.8\%). The estragole (methylchavicol) was not found in the essential oil from $O$. gratissimum. The compounds, Kovat's index and calculated retention index of the essential oil are showed in Table I.

The MIC values of $O$. gratissimum against $C$. neoformans clinical isolates observed in this study showed that the ethanolic extract and all fractions of this plant have antifungal activity. The chloroformic fraction of this plant at concentration of $62.5 \mu \mathrm{g} / \mathrm{ml}$ inhibited $92 \%$

TABLE I

Percentage composition of the essential oil from Ocimum gratissimum leaves

\begin{tabular}{lrrr}
\hline Compounds & \\
\hline Myrcene & $\mathrm{KI}^{b}$ & $\mathrm{RI}^{c}$ & $\%$ \\
$\alpha$-Terpinene & 991 & 996 & 0.34 \\
$p$-Cymene & 1018 & 1017 & 0.30 \\
(E)- $\beta$-Ocimene & 1026 & 1054 & 2.11 \\
$\gamma$-Terpinene & 1050 & 1052 & 0.49 \\
$p$-Cymenene & 1062 & 1061 & 3.06 \\
Terpin-4-ol & 1089 & 1087 & 0.26 \\
Thymol & 1177 & 1175 & 0.24 \\
Carvacrol & 1290 & 1288 & 9.80 \\
Eugenol & 1298 & 1295 & 0.28 \\
$\alpha$-Copaene & 1356 & 1357 & 57.82 \\
$\beta$-Caryophyllene & 1376 & 1375 & 0.11 \\
$\alpha$-Humulene & 1418 & 1417 & 3.03 \\
(E)- $\beta$-Farnesene & 1454 & 1454 & 0.31 \\
Germacrene D & 1458 & 1457 & 0.39 \\
cis- $\beta$-Guaieno & 1480 & 1482 & 0.79 \\
$\alpha-S e l i n e n e$ & 1490 & 1491 & 1.06 \\
(Z)- $\alpha$-Bisabolene & 1494 & 1493 & 0.45 \\
$\beta$-Sesquiphellandrene & 1504 & 1502 & 17.19 \\
Spathulenol & 1576 & 1521 & 0.24 \\
Caryophyllene oxide & 1581 & 1575 & 0.18 \\
\hline
\end{tabular}

$a$ : compounds are listed in order of their elution from a CBP-5 column; $b$ : Kòvat's Index (Adams 1995); $c$ : Calculated retention index (Van Den Doll \& Kratz 1963) 
of Cryptococcus isolates and the hexanoate fraction inhibited $8(40 \%)$ of these same isolates in a concentration of $250 \mu \mathrm{g} / \mathrm{ml}$. The natural product (eugenol) from $O$. gratissimum showed higher inhibition than essential oil. It was observed that the eugenol inhibited the growth of $16 \%$ of isolates of $C$. neoformans at concentration of 0.9 $\mu \mathrm{g} / \mathrm{ml}$ while the essential oil showed an inhibition of $8 \%$ of isolates at concentration of $125 \mu \mathrm{g} / \mathrm{ml}$. The sensitivity of the same fungal isolates to itraconazole showed a range MIC of 15.6 to $0.03 \mu \mathrm{g} / \mathrm{ml}$. It was verified that $16 \%$ were inhibited of growth by eugenol at concentrations below than $1 \mu \mathrm{g} / \mathrm{ml}$ while $24 \%$ of isolates were inhibited by itraconazole at concentrations below than $1 \mu \mathrm{g} / \mathrm{ml}$. The MIC ranges, $\mathrm{MIC}_{50}$ and $\mathrm{MIC}_{90}$ values of isolates of $C$. neoformans against plant extracts and itraconazole are showed in Table II. The MIC of $0.25 \mu \mathrm{g} / \mathrm{ml}$ was found to reference strain C. albicans ATCC 10231 for itraconazole. This value was within the standard acceptable range of MICs.

\section{DISCUSSION}

The chemical composition of the essential oil of $O$. gratissimum can change according with geographical distribution and daytime of collect. The chemical test result revealed that the constituents of $O$. gratissimum essential oil collected in Goiânia city, in this study, included eugenol, terpenoids, and thymol (Table I). Similar results were observed by Dubey et al. (2000), who verified citral, ethyl cinnamate chemotype, eugenol, linalol as the dominant constituents of $O$. gratissimum essential oil. On the other hand, Martins et al. (1999) did not find eugenol as constituent of the essential oil in O. gratissimum from Portugal Island.

The high concentration of eugenol, as main constituent of essential oil of $O$. gratissimum verified in our plant, confirm data shown by Vasconcelos Silva et al. (1999) that showed a higher content of eugenol in the collection at $12 \mathrm{~h}(98 \%)$ than in the collection at $17 \mathrm{~h}(11.3 \%)$.

Vincenzi et al. (2000) reported that estragole a naturally occurring genotoxic carcinogen in experimental animals after chronic exposure or after a few repeated doses can be present in $O$. gratissimum. The absence of estragole in our O. gratissimum oil permits its usage in phytomedicines.

All the extracts of $O$. gratissimum studied in our work showed activity in vitro towards $C$. neoformans by using agar dilution method. This method has been used for several searchers to determine the activity of plant against fungi (Steinmetz et al. 1995, Larshini et al. 1996). Investigation earlier has showed that $O$. gratissimum has activity against other fungi. Lima et al. (1993) and Nwosu and Okafor (1995) verified inhibition of growth of Trychophyton rubrum and T. mentagrophytes. Dubey et al. (2000) had already established that thymol a constituent of $O$. gratissimum essential oil was highly active against T. rubrum, T. mentagrophytes, C. neoformans, C. albicans, and Malassezia pachydermatis. In our work is important to note that $92 \%$ C. neoformans isolates were inhibited of growth at concentrations of $62.5 \mu \mathrm{g} / \mathrm{ml}$ by chloroformic fraction and $100 \%$ of these isolates were inhibited at 250 $\mu \mathrm{g} / \mathrm{ml}$ by essential oil and eugenol as verified in Table II.
TABLE II

In vitro antifungal activity of Ocimum gratissimum and itraconazole against 25 clinical isolates of Cryptococcus neoformans

\begin{tabular}{lccc}
\hline \multirow{2}{*}{ O. gratissimum } & \multicolumn{3}{c}{$\begin{array}{c}\text { Minimal inhibition } \\
\text { concentration }(\mathrm{MIC})\end{array}$} \\
\cline { 2 - 4 } & Range & $\mathrm{MIC}_{50}$ & $\mathrm{MIC}_{90}$ \\
\hline Ethanolic extract & $250>1000$ & 1000 & $>1000$ \\
Hexane fraction & $62.5-500$ & 250 & 500 \\
Chloroform fraction & $62.5-125$ & 62.5 & 62.5 \\
Ethyl acetate fraction & $250->1000$ & $>1000$ & $>1000$ \\
Essential oil & $125-250$ & 250 & 250 \\
Eugenol & $0.9-250$ & 250 & 250 \\
Itraconazole & $0.03-15.6$ & 3.9 & 15.6 \\
\hline
\end{tabular}

The results in vitro susceptibility tests of the fungal isolates to eugenol, main constituent of essential oil of $O$. gratissimum obtained in our work presented MIC values near to itraconazole for $16 \%$ of the isolates. However prior investigations are need for establishing comparison between plants and itraconazole activity.

The results suggest that the chloroformic fraction, essential oil and eugenol, constituents of $O$. gratissimum leaves, are important sources of new antifungal agents. This study open perspectives to find more effective drugs of vegetal origin in the treatment of fungal infections.

\section{ACKNOWLEDGMENTS}

To Dr José Realino de Paul (Faculdade de Farmácia, UFG) for authentication of plant sample.

\section{REFERENCES}

Adams RP 1995. Identification of Essential Oil Component by Chromatography/mass Spectroscopy, Allured Publishing Co., Carol Stream, Ilinois.

Alves SH, Cury AE 1992. Sensibilidade de leveduras do gênero Candida isoladas de pacientes com câncer, a antifúngicos poliênicos. Rev Inst Med Trop São Paulo 34: 251-254.

Alves SH, Lopes JO, Costa JM, Klock C 1997. Development of secondary resistance to fluconazole in $C$. neoformans isolated from a patients with AIDS. Rev Inst Med Trop São Paulo 39: 359-361.

Collazos J 2003. Opportunistic infections of the CNS in patients with AIDS: diagnosis and management. CNS Drugs 17: 869-887.

De Bedout C, Ordónez N, Gómez BL 1999. In vitro antifungal susceptibility of clinical isolates of Cryptococcus neoformans var. neoformans and C. neoformans var. gattii. Rev Iberoam Micol 16: 36-39.

Dromer F, Mathoulin S, Dupont B 1996. Comparison of the efficacy of amphothericin B and fluconazole in the treatment of cryptococcosis in human immunodeficiency virusnegative patients: retrospective analysis of 83 cases. Clin Infect Dis 22: 154-160.

Dubey NK, Tiwari TN, Mandin D, Andriamboavonjy H, Chaumont JP 2000. Antifungal properties of Ocimum gratissimum essential oil (ethyl cinnamate chemotype). 
Fitoterapia 71: 567-569.

Fernandes AMAP, Prado AL, Barata LES, Paulo MQ, Azevedo NR, Ferri PH 1997. A method to separate Lignoids from Vinola leaves. Phytochemical Analysis 8: 18-21.

Fernandes OFL, Passos XS, Souza LKH, Miranda ATB, Cerqueira CHPV, Silva MRR 2003. In vitro susceptibility characteristics of Cryptococcus neoformans varieties from AIDS patients in Goiânia, Brazil. Mem Inst Oswaldo Cruz. 98: 839-841.

Larshini M, Lazrek HB, Amarouch H, Jana M 1996. Investigation of antifungal and analgesic of extracts from Sium nodiflorum. J Ethnopharmacol 53: 105-110.

Lima EO, Gompertz OF, Giesbrecht AM, Paulo MQ 1993. In vitro antifungal activity of essential oils obtained from officinal plants against dermatophytes. Mycoses 36: 333-336.

Martins AP, Salgueiro LG, Vila R, Tomi F, Cañigueral S, Casanova J, Cunha, AP, Adzet T 1999. Composition of the essential oils of $O$. canum, $O$. gratissimum and $O$. minimum. Planta Med 65: 187-189.

Mitchell GT, Perfect JR 1995. Cryptococcosis in the Era of AIDS-100 years after the discovery of Cryptococcus neoformans. J Clin Microbiol 8: 515-548.

Momoff M, Parrish A 2003. Fluconazole- resistant cryptococcal meningitis. S Afr Med J 93: 444.

Nakamura CV, Nakamura T, Bando E, Melo AFN, Cortéz, DAG, Filho BPD 1999. Antibacterial activity of Ocimum gratissimum L. essential oil. Mem Inst Oswaldo Cruz 94: 675-678.

Nwosu MO, Okafor J 1995. Preliminary studies of the antifungal activities of some medicinal plants against Basidiobolus and some other pathogenic fungi. Mycoses 8: 191-195.

Passos XS, Castro AC, Pires JS, Garcia ACF, Campos FC, Fernandes OFL, Paula JR, Ferreira HD, Santos SC, Ferri PH, Silva MRR 2003. Composition and antifungal activity of the essential oils of Caryocar brasiliensis. Pharm Biology 41: 321-326.

Saag MS, Graybill RJ, Larsen RA, Pappas PG, Perfect JR, Powderly WG, Sobel JD, Dismukes WE 2000. Practice guidelines for the management of cryptococcal disease. Clin Infect Dis 30: 710-718.

Souza LKH, Oliveira CMA, Ferri PH, Santos SC, Oliveira Jr JG, Miranda ATB, Liao LM, Silva MRR 2002. Antifungal properties of Brazilian Cerrado plants. Braz J Microbiol 33: 247-249.

Steinmetz MD, Rascol JP, Régli P, Gargadennec A, Andary C 1995. In vitro antifungal of Polyporaceae against yeasts and dermatophytes. Mycoses 38: 305-309.

Terrel CL 1999. Antifungal agents. Part II. The azoles. Mayo Cli Proc 100: 74-78.

Van Den Doll H, Kratz PDJA 1963. Generalization of the retention index system including linear temperature programmed gas-liquid partition chromatography. J Chromatogr 11: 463-471.

Vasconcelos-Silva MG, Craveiro AA, Abreu Matos FJ, Machado MIL, Alencar JW 1999. Chemical variation during daytime of constituents of the essential oil of Ocimum gratissimum leaves. Fitoterapia 70: 32-34.

Vincenzi M, Silano M, Maialetti f, Scazzocchio B 2000. Constituents of aromatic plants: II Estragole. Fitoterapia 71 : 725-729. 